\title{
Characterization and in vitro properties of oral lactobacilli in breastfed infants
}

\author{
Nelly Romani Vestman ${ }^{1 *}$, Niklas Timby ${ }^{2}$, Pernilla Lif Holgerson ${ }^{1}$, Christine A Kressirer ${ }^{3,4}$, Rolf Claesson ${ }^{5}$, \\ Magnus Domellöf', Carina Öhman', Anne CR Tanner ${ }^{3,4}$, Olle Hernell ${ }^{2}$ and Ingegerd Johansson ${ }^{1}$
}

\begin{abstract}
Background: Lactobacillus species can contribute positively to general and oral health and are frequently acquired by breastfeeding in infancy. The present study aimed to identify oral lactobacilli in breast and formula-fed 4 monthold infants and to evaluate potential probiotic properties of the dominant Lactobacillus species detected. Saliva and oral swab samples were collected from 133 infants who were enrolled in a longitudinal study $(n=240)$ examining the effect of a new infant formula on child growth and development. Saliva was cultured and Lactobacillus isolates were identified from 16S rRNA gene sequences. Five L. gasseri isolates that differed in $16 \mathrm{~S}$ rRNA sequence were tested for their ability to inhibit growth of selected oral bacteria and for adhesion to oral tissues. Oral swab samples were analyzed by qPCR for Lactobacillus gasseri.
\end{abstract}

Results: 43 (32.3\%) infants were breastfed and 90 (67.7\%) were formula-fed with either a standard formula (43 out of 90) or formula supplemented with a milk fat globule membrane (MFGM) fraction (47 out of 90). Lactobacilli were cultured from saliva of $34.1 \%$ breastfed infants, but only in $4.7 \%$ of the standard and $9.3 \%$ of the MFGM supplemented formula-fed infants. L. gasseri was the most prevalent (88\% of Lactobacillus positive infants) of six Lactobacillus species detected. L. gasseri isolates inhibited Streptococcus mutans binding to saliva-coated hydroxyapatite, and inhibited growth of S. mutans, Streptococcus sobrinus, Actinomyces naes/undii, Actinomyces oris, Candida albicans and Fusobacterium nucleatum in a concentration dependent fashion. L. gasseri isolates bound to parotid and submandibular saliva, salivary gp340 and MUC7, and purified MFGM, and adhered to epithelial cells. L. gasseri was detected by qPCR in $29.7 \%$ of the oral swabs. Breastfed infants had significantly higher mean DNA levels of L. gasseri (2.14 pg/uL) than infants fed the standard (0.363 pg/uL) or MFGM (0.697 pg/uL) formula.

Conclusions: Lactobacilli colonized the oral cavity of breastfed infants significantly more frequently than formulafed infants. The dominant Lactobacillus was L. gasseri, which was detected at higher levels in breastfed than formula-fed infants and displayed probiotic traits in vitro.

Keywords: Lactobacillus, L.gasseri, Growth, Adhesion, Gp340, Breastfed infants

\section{Background}

Lactobacilli colonize the normal healthy gastrointestinal tract, including the oral cavity [1]. Lactobacillus species have health-promoting (probiotic) traits by altering the biofilm microbial composition [2] or by stimulating the host immune response [3]. Beneficial probiotic effects come from the activity of viable organisms [4]. Probiotic action of several Lactobacillus species and strains has been associated with reduction of chronic inflammatory

\footnotetext{
* Correspondence: nelly.romani.vestman@odont.umu.se

${ }^{1}$ Department of Odontology/Cariology section, Umeå University, Umeå, Sweden

Full list of author information is available at the end of the article
}

diseases [5,6] and weight regulation [7]. Lactobacilli can cause dental caries through their highly acidogenic and acid-tolerant characteristics [8], and are frequently detected in deep carious lesions [9]. Recent studies, however, suggest an additional beneficial role for oral lactobacilli [10]. Strains of Lactobacillus paracasei, Lactobacillus plantarum and Lactobacillus rhamnosus from caries-free subjects were found to inhibit in vitro growth of laboratory strains and clinical isolates of the cariogenic species Streptococcus mutans and Streptococcus sobrinus more efficiently than Lactobacillus strains isolated from caries-active subjects [11]. Further, in preschool children oral Lactobacillus acidophilus was associated with lack of caries [12].

\section{Biomed Central}


We recently reported that lactobacilli were detected in saliva from 3 month-old breastfed but not formula-fed infants [13], and preliminary findings indicated that Lactobacillus gasseri was the dominant salivary Lactobacillus. Early colonization of cariogenic pathogens, particularly Streptococcus mutans, can increase the risk of childhood caries [14]. If certain Lactobacillus strains can suppress $S$. mutans, it becomes important in caries risk assessment to determine which lactobacilli are acquired in infancy and whether the colonizing strains or species have probiotic potential. Few studies, however, have examined lactobacilli in infants and probiotic activity of strains.

Breast milk provides nutrition for the infant, bacteria that can impact the microbial composition of the gastrointestinal tract $[15,16]$, and components that can influence bacterial attachment and growth in the mouth, stomach and intestine [17-19]. The dominant constituents in milk are lipids, lactose, oligosaccharides and proteins [20], and the major energy source in milk is triglycerides and other fats. Fats are extruded from the epithelial cell as globules that are enveloped by the epithelial cell membrane, known as the "milk fat globule membrane" (MFGM) [21]. MFGM is rich in phospholipids, gangliosides, cholesterol and many biologically active proteins [21]. The MFGM fraction participates in cellular processes and defense mechanisms in the newborn, including those involved in microbial acquisition $[22,23]$. MFGM proteins comprise $1-4 \%$ of the total milk protein [22], and includes seven major protein components: alpha-lactalbumin, lysozyme precursor, beta-casein, clusterin, lactotransferrin, polymeric immunoglobulin receptor precursor, and human milk fat globule EGF-factor 8 protein $[23,24]$. Many of these proteins are glycosylated [23]. MFGM adheres to Lactobacillus reuteri [25], but does not affect L. acidophilus or L. gasseri [26].

The aim of the present study was $(i)$ to quantitate total lactobacilli in saliva from 4 month-old breastfed and formula-fed infants, (ii) to identify the dominant Lactobacillus species and (iii) evaluate possible probiotic traits of the most prevalent Lactobacillus species by analyzing their adhesion to host exocrine secretions and tissues (saliva, milk, purified human MFGM fraction, and epithelial cells), and their effect on growth of selected oral species in vitro. Here we report that oral lactobacilli are detected more frequently in breastfed than formula-fed infants, and that L. gasseri, the dominant species detected, has probiotic traits.

\section{Methods}

\section{Study group}

Four month-old infants were recruited from an ongoing study evaluating a novel infant formula (NCT00624689, total $n=240$, PI M. Domellöf, Umeå University, Sweden). Details of the parent study will be reported elsewhere (unpublished data, Timby N, Hernell O, Lönnerdal B, Domellöf $\mathrm{M}$ ). Infants entering the parent study between September 2009 and June 2012 were invited to participate in the current study that added oral microbial sampling (saliva and oral mucosal swabs). Inclusion criteria were: 0-2 months old, birth weight 2,500-4,500 g, full term, and exclusively breast or formula-fed at the time of recruitment. The exclusion criterion was chronic illness. The parent study population aimed to recruit twice as many formula- as breastfed infants. Formula-fed infants received either a standard infant formula (Semper $A B$, Sundbyberg, Sweden) or an infant formula containing MFGM fraction (LACPRODAN ${ }^{\circledR}$ MFGM-10, Arla Foods Ingredients, Viby, Denmark). Infant body weight and length at birth and recruitment, vaginal or C-section delivery and use of antibiotics was obtained from medical records. Breast or bottle feeding information including type of formula given to infants before recruitment and consumption of probiotics products were obtained from infant's diet records.

The current study population of 133 infants, comprised 43 breastfed infants, 43 standard formula-fed infants and 47 infants fed the MFGM enriched formula. Saliva could not be collected from six infants ( 2 breastfed, and 4 MFGM formula-fed), and oral swabs were not obtained from five infants ( 2 breastfed, 3 MFGM formulafed). One standard formula-fed infant had received antibiotics at birth and one MFGM enriched formula-fed infant received antibiotics at 3 months of age. Twenty-five infants had been given commercially available probiotic oral drops (Semper Magdroppar, BioGaia AB, Lund, Sweden) containing L. reuteri ATCC $17938\left(\sim 10^{8}\right.$ CFU in 5 drops) at $1,2,3$ or 4 months of age. Infants given probiotic drops did not differ between the three feeding groups ( $\mathrm{p} \geq 0.401)$.

The study was approved by the Regional Ethical Review Board in Umeå, Sweden. All caregivers signed informed consent when recruited.

\section{Culture of salivary lactobacilli and characterization of isolates}

Whole saliva was collected from the infants and Lactobacillus cultured using selective medium as previously described [13]. Up to 30 isolates were selected from each plate and were identified by comparing $16 \mathrm{~S}$ rRNA gene sequences to databases HOMD (http://www.homd.org) and NCBI (http://blast.ncbi.nlm.nih.gov/Blast.cgi).

\section{qPCR for L. gasseri in mucosal swabs}

The mucosa of the cheeks, the tongue and alveolar ridges of the infants were swabbed using sterile cotton swabs (Applimed SA, Chatel-St-Denis, Switzerland). Samples storage, DNA purification and L. gasseri level quantification by qPCR were as described previously $[13,27]$. 


\section{Growth inhibition by L. gasseri Cultural conditions and bacterial strains used in growth inhibition tests}

Lactobacillus isolates were maintained on de Man, Rogosa, Sharpe Agar (MRS) (Fluka, Buchs, Switzerland) and grown in MRS broth. S. mutans strains Ingbritt, NG8, LT11 and JBP, S. sobrinus strains OMZ176 and 6715, Actinomyces naeslundii genospecies 1 strains ATCC 35334 and ATCC 29952, and Actinomyces oris (previously A. naeslundii genospecies 2) strains T14V and M4366 were maintained on Columbia agar plates (Alpha BioScience, Baltimore, Maryland, USA) supplemented with $5 \%$ horse blood (CAB) and grown in Todd-Hewitt broth (Fluka). Fusobacterium nucleatum strains ATCC 25586 and UJA11-a were maintained on Fastidious Anaerobe Agar (FAA, Lab M, Bury, UK) and grown in Peptone yeast extract broth (PY, Sigma-Aldrich Co., St. Louis, Missouri, USA). Bacteria were cultured anaerobically at $37^{\circ} \mathrm{C}$ for $48-72 \mathrm{~h}$ (maintenance) or $24 \mathrm{~h}$ (growth). Candida albicans strains ATCC 10231, ATCC 28366, GDH3339, GDH18 and CA1957 were maintained on Difco ${ }^{\mathrm{Ts}}$ Sabouraud Maltose Agar (Becton, Dickinson and Company, Sparks, Nevada, USA) for $20 \mathrm{~h}$ and grown in Difco ${ }^{\mathrm{TM}}$ Sabouraud Maltose broth (Becton, Dickinson and Company) overnight under aerobic conditions at $37^{\circ} \mathrm{C}$.

\section{Growth inhibition by agar overlay}

Five L. gasseri isolates with single nucleotide differences in the $16 \mathrm{~S}$ rRNA gene from infants (isolate B1, B16, L10, A241 and A271) and the L. gasseri type strain CCUG 31451 (Culture Collection University Göteborg, Göteborg, Sweden) were tested for growth inhibition using an agar overlay method [11,13]. Oral bacteria tested were $S$. mutans, S. sobrinus, A. naeslundii, A. oris (top layers M17 agar (May and Baker, Dagenham, England), supplemented with lactose)), F. nucleatum and C. albicans (top layers same as species growth media). Agar plates without lactobacilli were negative controls. Growth was scored: $0=$ no growth, complete inhibition; score 1 = moderate growth, slight inhibition; and score 2 = same or more growth as the control, no inhibition [11].

\section{Adhesion and aggregation tests for L. gasseri Saliva, milk and MFGM fractions}

Parotid saliva from two healthy adult donors and submandibular/sublingual saliva from one adult donor were collected into ice-chilled vials and used immediately or stored in aliquots at $-80^{\circ} \mathrm{C}$. Sterile Lashley cups were used for ductal parotid saliva collection and a custom made device for submandibular/sublingual saliva collection [28]. Breast milk from two healthy mothers was defatted [19] and stored at $-80^{\circ} \mathrm{C}$. Saliva and defatted milk were diluted 1:1 in adhesion buffer (ADH; $50 \mathrm{mM} \mathrm{KCl,} 1 \mathrm{mM} \mathrm{CaCl}_{2}$, $0.1 \mathrm{mM} \mathrm{MgCl} 2,1 \mathrm{mM} \mathrm{K} \mathrm{HPO}_{4}, 1 \mathrm{mM} \mathrm{KH_{2 }} \mathrm{PO}_{4}, \mathrm{pH}$ 7.4) and freeze-dried purified LACPRODAN ${ }^{\circledR}$ MFGM-10 diluted in $\mathrm{ADH}(1 \mathrm{mg} / \mathrm{mL})$ were used in the experiments.

\section{L. gasseri adhesion to host ligand coated hydroxyapatite}

Following overnight culture on MRS agar, cells from $L$. gasseri strains B1, B16, L10, A241 and A271, and CCUG 31451 were harvested and transferred to $80 \mu \mathrm{L}$ phosphate buffered saline (PBS: $25 \mathrm{mM}$ phosphate, $85 \mathrm{mM}$ $\mathrm{NaCl}, \mathrm{pH}$ 7.4) with $100 \mu \mathrm{Ci}$ Trans [35 $5^{\mathrm{S}}$-labeled-methionine (ICN Pharmaceuticals Inc., Irvine, California, USA). After overnight culture on $\mathrm{CAB}$ agar at $37^{\circ} \mathrm{C}$ in an anaerobic chamber, radiolabeled cells were harvested, washed three times in ADH buffer, and bacterial concentration determined by comparing the turbidity against a standard curve. S. mutans strain Ingbritt was cultured and radiolabeled as described [19].

Adhesion of L. gasseri to host ligands coated hydroxyapatite (HA) was performed as described [19,29]. Briefly, $5 \mathrm{mg}$ HA beads (Macro-Prep Ceramic Hydroxyapatite Type II, $80 \mu \mathrm{m}$, Bio-Rad, Hercules, California, USA) were coated separately with human parotid saliva, submandibular/sublingual saliva, human defatted milk or LACPRODAN-MFGM-10 during end-over-end agitation for $1 \mathrm{~h}$ at room temperature. After washing and blocking, coated beads were incubated with radiolabeled L. gasseri $\left(125 \mu \mathrm{l}\right.$ of $\sim 1 \times 10^{9}$ cells) and the bacteria were allowed to adhere for $1 \mathrm{~h}$, after which the unbound bacteria were washed away. The numbers of attached lactobacilli were determined by scintillation counting.

Bacterial adhesion inhibition [19] was tested in two sets of experiments. First, L. gasseri strains were pre-incubated separately with human parotid and submandibular/sublingual saliva for $30 \mathrm{~min}$ at $37^{\circ} \mathrm{C}$. After removal of $L$. gasseri cells and HA coating with pre-incubated ligand, radiolabeled $S$. mutans strain Ingbritt was allowed to adhere as described above. In the second set of experiments $S$. mutans was used for pre-incubation, and radiolabeled L. gasseri allowed to adhere for $1 \mathrm{~h}$. All experiments were performed in triplicate and repeated on two separate occasions.

\section{L. gasseri aggregation}

Equal volumes of a bacterial cell suspension $(20 \mu \mathrm{L}$, $1 \times 10^{9}$ cells $/ \mathrm{mL}$ ) with parotid, submandibular/sublingual saliva, defatted human milk or LACPRODAN ${ }^{\curvearrowleft}$ MFGM$10(1 \mathrm{mg} / \mathrm{mL})$ were agitated on a glass slide for $5 \mathrm{~min}$ at $37^{\circ} \mathrm{C}$. The size of visible aggregates was rated on a scale from 0 to 4 under microscopic inspection [30].

\section{L. gasseri adhesion to human epithelial cells}

The adhesive capacity of $L$. gasseri was examined using Human primary gingival epithelial HGEPp.05 purchased from CellnTec (CellnTec Advanced Cell Systems AG, Bern, Switzerland). Cells were cultured in CnT-24 cell 
culture medium (Celln Tec) at $37^{\circ} \mathrm{C}$ in a $5 \% \mathrm{CO}_{2}$ incubator. The adhesion assay was performed as previously described [31]. Briefly, cells were seeded at different concentrations $\left(0-10^{5}\right.$ cells $\left./ \mathrm{cm}^{2}\right)$ and cultured on 4-well Lab-Tek $^{\text {Tax }}$ II Chamber Slide ${ }^{\mathrm{Ta}}$ System glass slides (Nunc, Roskilde, Denmark) at $37^{\circ} \mathrm{C}$ in a $5 \% \mathrm{CO}_{2}$ incubator. Cells were then fixed in 30\% acetone in methanol and the slides were blocked with $1 \%$ BSA in PBST $(25 \mathrm{mM}$ phosphate, $85 \mathrm{mM} \mathrm{NaCl}, 0,05 \%$ Tween-20, pH 7.4) for $1 \mathrm{~h}$.

L. gasseri strains were cultured on MRS agar for $24 \mathrm{~h}$ at $37^{\circ} \mathrm{C}$ in an anaerobic chamber and labeled with fluorescein isothiocyanate (FITC) [32]. Lactobacilli cell density was adjusted to $\mathrm{OD}_{600}=0.2$ and stored at $-80^{\circ} \mathrm{C}$ until use. Before addition to the gingival epithelial cell coated slides, the bacteria were diluted 4 times in $1 \%$ BSA in PBST. After incubation for $2 \mathrm{~h}$, the slides were washed 300 times in PBST (buffer changed every 100 dips) and mounted for microscopy evaluation. All images were acquired using a Zeiss imager Z1 upright microscopic (Carlzeiss, Stockholm, Sweden) and software Zen 2011 with 400× optical magnification.

\section{Salivary host ligands for L. gasseri}

The presence of binding epitopes in salivary gp340 and MUC7 were evaluated by Western blot [33] for five $L$. gasseri isolates (B1, B16, L10, A241, A271) and strain CCUG 31451. Briefly, $0.5 \times 10^{8}$ cells were suspended in 0.5 $\mathrm{mL} \mathrm{KCl}$ buffer $\left(50 \mathrm{mM} \mathrm{KCl}, 0.35 \mathrm{mM} \mathrm{K}_{2} \mathrm{HPO}_{4}, 0.65 \mathrm{mM}\right.$ $\mathrm{KH}_{2} \mathrm{PO}_{4}, 1.0 \mathrm{mM} \mathrm{CaCl} 20,1 \mathrm{mM} \mathrm{MgCl}$, $\mathrm{pH}$ 6.5) and incubated under slow rotation for $1 \mathrm{~h}$ at room temperature with $0.5 \mathrm{~mL}$ parotid or submandibular/sublingual saliva diluted 1:1 in $\mathrm{KCl}$ buffer. Bacteria were separated from unbound salivary components by centrifugation at $13,000 \mathrm{rpm}$ for $10 \mathrm{~min}$ at room temperature. To release the bound proteins, the bacterial pellets were boiled with $2 \%$ sodium dodecyl sulfate (SDS) for $10 \mathrm{~min}$ (for detection of MUC7 $10 \mathrm{mM}$ Dithiothreitol (DTT) was also added) and separated on $5 \%$ Tris- $\mathrm{HCl}$ gel (BioRad Laboratories, Hercules, Massachusetts, USA). Proteins were transferred to a (polyvinylidene difluoride (PVDF) membrane (Millipore, Bedford, Massachusetts, USA). The membranes were blocked and epitopes detected with monoclonal antibodies against gp340 (mAb143) [34] or LUM7-2 [35]. Membranes were washed with TBS (gp340) or PBS (MUC7) and incubated with HRP-conjugated antimouse (SAB-100, Stressgen, Victoria, Canada) for gp340 or HRP-conjugated anti-rabbit (P0448, DAKO, Glostrup, Denmark) for MUC7 and detected using Super Signal west Dura Extended Duration Substrate (Thermo Scientific, Rockford, IL, USA).

\section{Data processing and statistical analyses}

The power calculation for the parent study was based on body weight as main outcome [36] with a statistical power of $80 \%$ and a level of significance of $0.05 \%$ (unpublished data, Timby N, Hernell O, Lönnerdal B and Domellöf M). Based on previous investigations [37], the number of infants included in this study was sufficient to detect a difference in bacterial colonization pattern.

Data handling and statistical analyses were performed using PASW Statistics 20 (IBM Corporation Route 100, Somers, New York, USA). Anthropometric measures for infants were averaged, and means with 95\% CI reported. Differences between means were tested using analysis of variance (ANOVA) followed by a Bonferroni post hoc test. Differences between means for lactobacilli detected in saliva and swabs were tested using generalized linear modeling adjusted for delivery method and exposure to probiotic drops at 4 months. L. gasseri detected in swabs was additionally adjusted for amount of DNA. Categorical data are presented as proportions (\%) and differences between groups were tested with a $\mathrm{Chi}^{2}$ test. A p-value $<0.05$ was considered statistically significant.

Multivariate partial least squares analysis (PLS) was performed (SIMCA $\mathrm{P}+$, version 12.0, Umetrics $\mathrm{AB}$, Umeå, Sweden) as previously described [38,39]. Cross-validation $\left(Q^{2}\right.$ values) was performed by a systematic prediction of $1 / 7^{\text {th }}$ of the data by the remaining $6 / 7^{\text {th }}$ of the data. The importance of each variable in the model was displayed in a loading scatter plot. $R^{2}$ - and $Q^{2}$-values give the capacity of the $\mathrm{x}$-variables to explain $\left(\mathrm{R}^{2}\right)$ and predict $\left(\mathrm{Q}^{2}\right)$ the outcome.

\section{Results}

Among the 133 infants, the proportions of boys and girls, infants delivered vaginally, mean body weight and length at birth and at 4 months of age (screening age) did not differ significantly between infants fed breast milk, the standard formula or the MFGM-enriched formula (Table 1). This observation was not affected by exclusion of infants given antibiotics or probiotic drops.

\section{Total cultivable Lactobacillus in infant saliva}

Lactobacilli were cultured from saliva of $34.1 \%(n=14)$ of the breastfed infants compared with $4.7 \%(\mathrm{n}=2)$ and $9.3 \%$ $(n=4)$ of the standard and MFGM enriched formula-fed infants, respectively ( $<<0.001$; Table 1$)$. Partial least square regression (PLS) identified a feeding method (breastfeeding), L. gasseri in saliva, and L. gasseri (qPCR) in oral swabs as significantly influential for total numbers of lactobacilli/mL in saliva (dependent variable) (Figure 1A). Exposure to probiotic drops and delivery mode were positively associated with presence of lactobacilli but to a lower degree. The explanatory power of the model was $74.2 \%\left(R^{2}=0.742\right)$ and the predictive power $61.4 \%$ $\left(\mathrm{Q}^{2}=0.614\right)$. Mean CFU/mL saliva of lactobacilli $\left(\log _{10}\right)$, standardized for the potential confounders probiotic drops and delivery method, were significantly higher in 
Table 1 Study population characteristics and Lactobacillus detection by feeding method

\begin{tabular}{|c|c|c|c|c|}
\hline & Breastfed $(n=43)$ & Standard formula $(n=43)$ & MFGM formula $(n=47)$ & p-value \\
\hline Gender (boys/girls) $^{1}$ & $18 / 25$ & $23 / 20$ & $25 / 22$ & 0.216 \\
\hline Vaginal delivery (\% yes) $^{1}$ & 95.3 & 88.4 & 83.0 & 0.095 \\
\hline \multicolumn{5}{|l|}{ Weight (gram) $)^{2}$} \\
\hline At birth & $3,610(3,492-3,728)$ & $3,481(3,332-3,630)$ & $3,552(3,444-3,660)$ & 0.352 \\
\hline At 4 months of age & $6,742(6,548-6,935)$ & $6,850(6,575-7,126)$ & $6,859(6,670-7,049)$ & 0.704 \\
\hline \multicolumn{5}{|l|}{ Length $(\mathrm{cm})^{2}$} \\
\hline At birth & $50.5(50.0-51.1)$ & $50.3(49.7-50.9)$ & $50.6(50.0-51.1)$ & 0.739 \\
\hline At 4 months of age & $63.9(63.3-64.5)$ & $63.7(62.9-64.6)$ & $64.3(63.7-64.9)$ & 0.522 \\
\hline CFU lactobacilli/mL of saliva $\left(\log _{10}\right)^{3}$ & $1.22(0.20)^{a, b}$ & $0.15(0.19)^{\mathrm{a}}$ & $0.28(0.19)^{b}$ & $<0.001$ \\
\hline \multicolumn{5}{|l|}{$\%$ (n) with lactobacilli cultured in saliva ${ }^{1}$} \\
\hline Among all infants $(n=127)$ & $34.1 \%(14)^{a, b}$ & $4.7 \%(2)^{a}$ & $9.3 \%(4)^{b}$ & $<0.001$ \\
\hline $\begin{array}{l}\text { Among infants who never had antibiotics } \\
\text { or probiotics }(n=106)\end{array}$ & $33.3 \%(10)^{a, b}$ & $5.6 \%(2)^{a}$ & $11.8 \%(4)^{b}$ & 0.006 \\
\hline Among vaginally delivered infants ( $n=118)$ & $35.9 \%(14)^{a, b}$ & $2.6 \%(1)^{a}$ & $8.3 \%(3)^{b}$ & $<0.001$ \\
\hline$\%(n)$ infants with salivary isolates of L. gasseri ${ }^{1}$ & $29.3 \%(12)^{a, b}$ & $2.4 \%(1)^{a}$ & $7.0 \%(3)^{b}$ & $<0.001$ \\
\hline 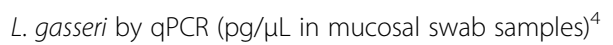 & $2.14(0.74)^{\mathrm{a}}$ & $0.31(0.70)^{\mathrm{a}}$ & $0.74(0.68)$ & $0.097^{4}$ \\
\hline
\end{tabular}

${ }^{1}$ Differences in proportions between feeding group numbers were tested with $\mathrm{Chi}^{2}$ test. Shared superscript letters ${ }^{(a \text { and b) }}$ indicate differences between groups when tested pairwise $(\mathrm{p} \leq 0.008)$.

2 Data are presented as mean $(95 \% \mathrm{Cl})$ and differences between group means were tested with ANOVA.

${ }^{3}$ Data are presented as mean (SE). Means are adjusted for delivery mode and exposure to probiotic drops at 4 months using generalized linear modelling $\left(p=0.012\right.$, one sided test). Shared superscript letters ${ }^{(a \text { and } b)}$ indicate groups that differ significant when tested pairwise ( $p$-value $\left.\leq 0.01\right)$. The $p$-value between the two formula groups was $\mathrm{p}=0.439$.

${ }^{4}$ Data are presented as mean (SE). Means are adjusted for delivery mode, exposure to probiotic drops at 4 months (yes/no) and amount of DNA using generalized linear modelling. Shared superscript letter ${ }^{(a)}$ indicates the groups that differ significantly when tested pairwise (one sided). Table 1 shows p-value between groups $(p=0.097)$. P-values for the breastfed versus the standard formula group was $p=0.040$ and breastfed versus MFGM formula group $p=0.089$, and between the two formula groups $p=0.329 .6 .75 \times 10^{5} \mathrm{pg} / \mathrm{mL}$ correspond to $5.9 \times 10^{7} \mathrm{CFU}$ L. gasseri cells $/ \mathrm{mL}$. Employing number of bacteria/mL in the regression model leads to identical results.

breastfed infants than in standard and MFGM formulafed infants, $(\mathrm{p} \leq 0.001$; Table 1). Presence and mean levels of salivary lactobacilli were approximately twice as high in the MFGM group than the standard formula group, but the difference was not statistically significant. Restricting the analyses to vaginally delivered infants and those who never received antibiotics and/or probiotic drops did not change findings (Table 1).

\section{L. gasseri in saliva and oral swabs}

307 putative Lactobacillus isolates from saliva were identified from 16S rRNA gene sequences as L. gasseri (78.8\%), Lactobacillus fermentum (8.7\%), L. reuteri (7.2\%), Lactobacillus casei/rhamnosus (3.3\%), L. paracasei $(1.3 \%)$ and $L$. plantarum (0.7\%) (Figure 2). L. gasseri was detected in $88 \%$ of the Lactobacillus positive infants. The distribution of Lactobacillus species detected in infants is in Table 2. Only one Lactobacillus species was detected in most infants (85\%) (footnote Table 2).

L. gasseri was detected by qPCR in $29.7 \%$ of 128 oral swabs analyzed. Generalized univariate analysis indicated that breastfed infants had significantly higher mean levels of $L$. gasseri in oral swabs than infants fed a standard formula ( $\mathrm{p}=0.04$, footnote Table 1 ) but not the MFGM formula. There was, however, no statistically significant difference between the three feeding groups when analyzed together $(\mathrm{p}=0.097)$. Means were standardized for the potential confounders of exposure to probiotic drops at 4 months, delivery mode and total DNA. In infants with cultivable salivary lactobacilli, $42.1 \%$ were positive for $L$. gasseri by $\mathrm{qPCR}$ in mucosal swabs ( $\mathrm{p}=0.190)$, and $53.3 \%$ were $L$. gasseri positive by $\mathrm{qPCR}$ in mucosal swabs and from sequenced salivary isolates $(\mathrm{p}=0.033)$.

PLS modeling with feeding groups as dependent variables indicated that total Lactobacillius counts $/ \mathrm{mL}$ of saliva, L. gasseri in saliva, probiotic drops at 4 month of age, and L. gasseri in oral swabs (qPCR) were influential (Figure 1B). The explanatory power of the model was $13.4 \%\left(R^{2}=0.134\right)$ and the predictive power $10.3 \%$ $\left(Q^{2}=0.103\right)$.

\section{L. gasseri growth inhibition on oral bacteria}

Five L. gasseri isolates (B1, B16, L10, A241, A274) and the $L$. gasseri type strain inhibited growth of $F$. nucleatum strains ATCC 25586 and UJA11, A. naeslundii genospecies1 strains ATCC 35334 and ATCC 29952, A. oris (previously A. naeslundii 2) strains T14V and M4366, S. mutans strains Ingbritt, NG8, LT11 and JBP, S. sobrinus 

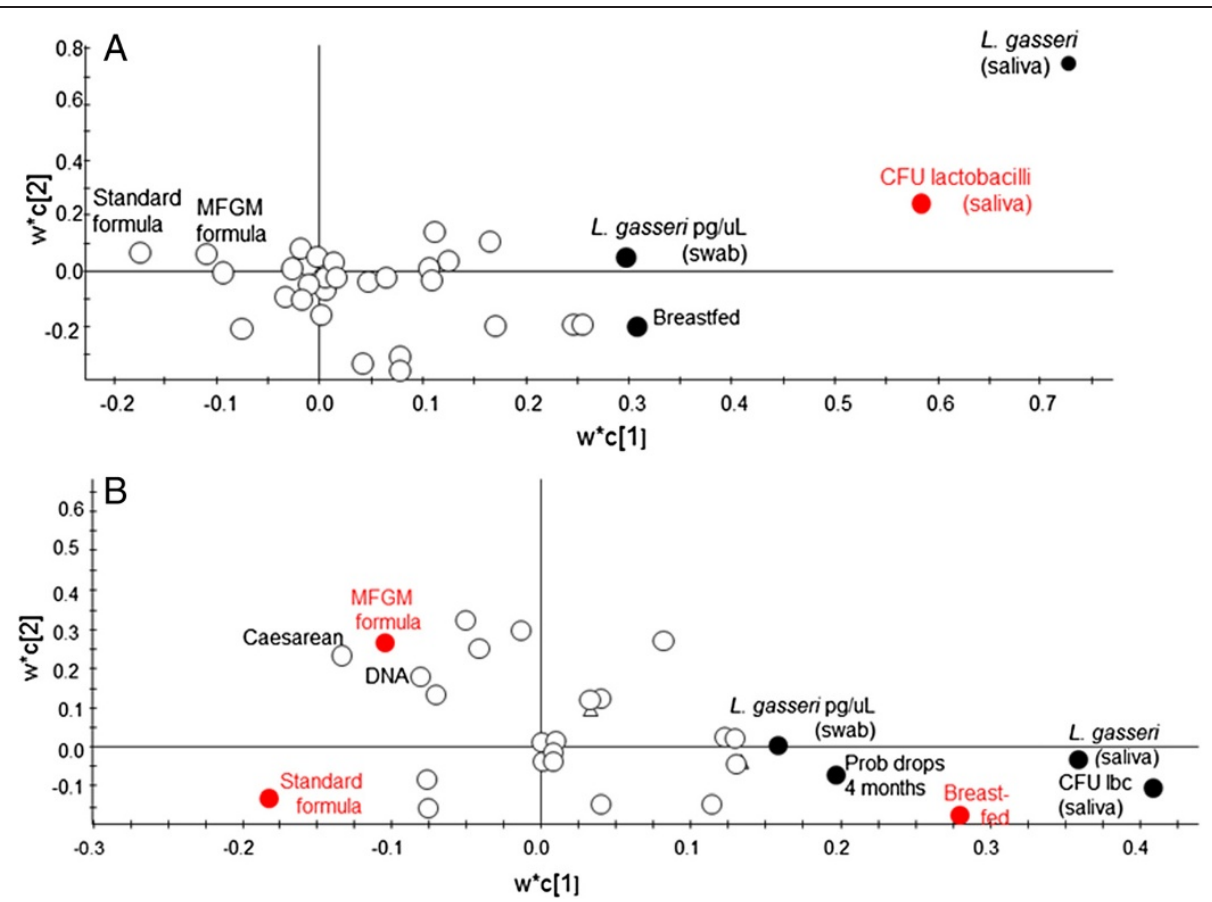

Figure 1 Variable importance for Lactobacillus counts and feeding groups. Partial least squares discriminant analysis identified variables influential for (A) Total number of Lactobacillus/mL saliva and (B) Feeding groups. Characteristics associated with the outcome variables (red circle symbol) were considered to be potential confounders and were adjusted for in statistical analysis.

strains OMZ176 and 6715, and C. albicans strains ATCC 10231, ATCC 28366, GDH3339, GDH18 and CA1957, in a concentration dependent fashion (Figure 3A). All $L$. gasseri strains, inhibited F. nucleatum the most and $C$. albicans the least.

\section{L. gasseri binding to host receptors in saliva and milk}

More L. gasseri B16 cells bound to hydroxyapatite coated with submandibular/sublingual saliva (27.3\% cells bound) or parotid saliva (20.2\% cells bound) than other strains. There was less avid binding to purified bovine MFGM fraction (13\% cells bound), and binding to human milk

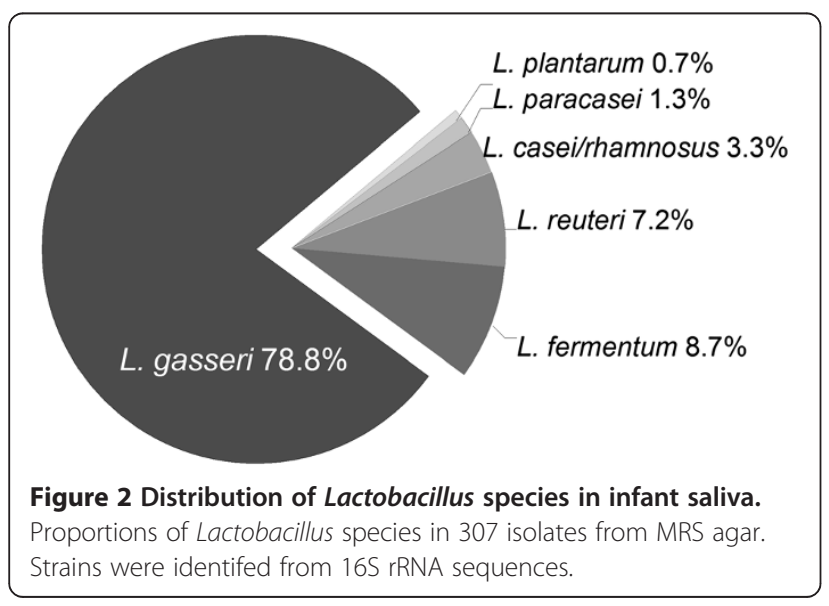

did not exceed binding to the buffer control (Figure 3B). The binding pattern was similar for all L. gasseri strains, although the percentages of bound bacterial cells were slightly lower for four isolates than the type strain and isolate B16 (Table 3). Aggregation of L. gasseri cells by saliva showed a similar adhesion pattern to saliva-coated hydroxyapatite for all five isolates and the type strain (Table 3). Aggregation by submandibular/sublingual saliva was highest (score 3), followed by parotid saliva (score 2) and MFGM (score 2) (Table 3) and human milk (score 1) (data not shown).

Adhesion of $S$. mutans strain Ingbritt to parotid and submandibular/sublingual saliva decreased significantly after pre-incubation of saliva with $L$. gasseri strain B16 (Figure 3C). A similar pattern was observed for L. gasseri binding after pre-incubation of saliva with $S$. mutans.

Gp340 $(\mathrm{mw}=340 \mathrm{kDa})$ was not detected by Western blot analysis with mAb143 antibodies in L. gasseri isolate B16 (Figure 4, upper panels A, lane 1), but gp340 was detected in parotid (Figure 4, upper panels A, lane 2) and submandibular saliva (Figure 4, upper panels A, lanes 6). The levels of gp340 were reduced in both salivas after incubation with L. gasseri (Figure 4, upper panels A, lane 3 and 7). Furthermore, bound gp340 was detected on L. gasseri (Figure 4, upper panels A, lanes 4 and 8) after incubation with saliva, and SDS treatment released gp340 bound to L. gasseri (Figure 4, upper panels A and B, lanes 5 and 9). Similar results were 
Table 2 Lactobacillus species isolated from 4-month- old infants

\begin{tabular}{|c|c|c|c|c|c|c|c|c|c|c|c|}
\hline \multirow[b]{3}{*}{ Sample } & \multirow[b]{3}{*}{ Feeding mode } & \multicolumn{6}{|c|}{ Lactobacillus species } & \multirow{2}{*}{\multicolumn{4}{|c|}{$\frac{\text { Exposure to probiotics }}{\text { (age in months) }}$}} \\
\hline & & \multicolumn{6}{|c|}{$(\% \text { of isolated colonies per infant) })^{1}$} & & & & \\
\hline & & L. gasseri & L. fermentum & L. reuteri & L. casei/ L. rhamnosus & L. paracasei & L. plantarum & 1 & 2 & 3 & 4 \\
\hline 1 & Breastfed & 100 & & & & & & & & + & + \\
\hline 2 & Breastfed & 100 & & & & & & & + & + & \\
\hline $3-10$ & Breastfed & 100 & & & & & & & & & \\
\hline 11 & Breastfed & 3.5 & 84 & & & 12.5 & & & & & \\
\hline 12 & Breastfed & 3.8 & & & & & 96.2 & & & & \\
\hline 13,14 & Breastfed & & & 100 & & & & & + & + & + \\
\hline 15 & Standard formula & 50 & & & 50 & & & & & & \\
\hline 16 & Standard formula & & & & & & 100 & & & & \\
\hline $17-19$ & MFGM formula ${ }^{\#}$ & 100 & & & & & & & & & \\
\hline 20 & MFGM formula ${ }^{\#}$ & & & 100 & & & & & & & \\
\hline
\end{tabular}

${ }^{1}$ One species was found in 17 infants (85\%), two species in two infants (samples 12, 15), and three species in one infant (sample 11).

\# Formula supplemented with a milk fat globule membrane fraction.

observed for S. mutans strain Ingbritt (Figures 4B, upper panels). The six additional isolates of $L$. gasseri also adhered to gp340 (Figures 4C and D, upper panels).

MUC7 ( $\mathrm{mw} \approx 150 \mathrm{kDa}$ ) was detected using Western blot analysis with mAb LUM7-2 antibodies in submandibular saliva (Figure 4, lower panels A and B, lane 6, lower panel D lane 1) but not in parotid saliva (data not shown). MUC7 levels were reduced in submandibular saliva after incubation with $L$. gasseri (Figure 4, lower panel A, lane 7) and S. mutans (Figure 4, lower panels B, lane 7). MUC7 was detected bound to L. gasseri (Figure 4, lower panel A, lane 8) and S. mutans (Figure 4, lower panel $\mathrm{B}$, lane 8) after incubation with submandibular saliva. SDS treatment released the MUC7 bound to $L$. gasseri (Figure 4, lower panel A, lane 9) and to S. mutans (Figure 4, lower panels B, lane 9). Similar results were observed for MUC7 binding to six additional isolates of $L$. gasseri (Figure 4D, lower panel).

\section{L. gasseri binds to human epithelial cells}

Adherence of FITC-tagged $L$. gasseri strains was detected by fluorescence microscopy as illustrated for strain A274 (Figure 5). All $L$ gasseri strains were observed only adjacent to epithelial cells.

\section{Discussion}

In this study lactobacilli were detected more frequently in breastfed than formula-fed 4 month-old infants in saliva and mucosal swab samples as we previously observed in a different population of infants [13]. L. gasseri was the dominant Lactobacillus species detected, which was identified from 16S RNA gene sequences of isolates. Probiotic potential of $L$. gasseri was found to include growth inhibition of $F$. nucleatum, A. naeslundii, A. oris, $S$. sobrinus and C. albicans in addition to the previously reported S. mutans and S. sanguinis [13]. Other characteristics of $L$. gasseri were inhibition of adhesion to hydroxyapatite in the presence of saliva, salivary gp 40 and MUC7 suggesting possible mechanisms for probiotic activity.

The infants sampled were recruited from a randomized clinical trial of MFGM supplemented infant formula compared with a standard formula and breastfeeding. Compliance to the feeding regimens was acceptable according to diet records obtained from the parent study. Infants recruited into the parent study were between 0 and 2 months of age. The estimated intake of breast milk at study enrollment was similar in the standard formula and the MFGM formula groups. When infants were sampled at 4 months of age, they had been exposed to either formula or breast milk for two months [40,41]. The lack of difference between the formula-fed groups suggests that this period might not have been long enough or that the different formulations do not induce changes in the oral microbiota. Previous studies, however, have observed that feeding mode, method of delivery, use of antibiotics and probiotic products may influence the oral and intestinal microbiota $[2,13,40,42]$. We accounted for these possible confounders in the PLS analysis, and found they had only marginally influential for feeding group allocations and total lactobacilli counts.

L. gasseri was identified as the dominant Lactobacillus species in the oral cavities of the 4 month-old infants. This is consistent with previous studies on Lactobacillus detection in the oral cavity $[13,16]$ and the infant gut $[43,44]$. L. gasseri is a member of the L. acidophilus complex, which includes L. acidophilus, Lactobacillus amylovorus, Lactobacillus crispatus, Lactobacillus gallinarum and Lactobacillus johnsonii [45]. Strains belonging to the L. gasseri complex have been extensively studied for "probiotic" 

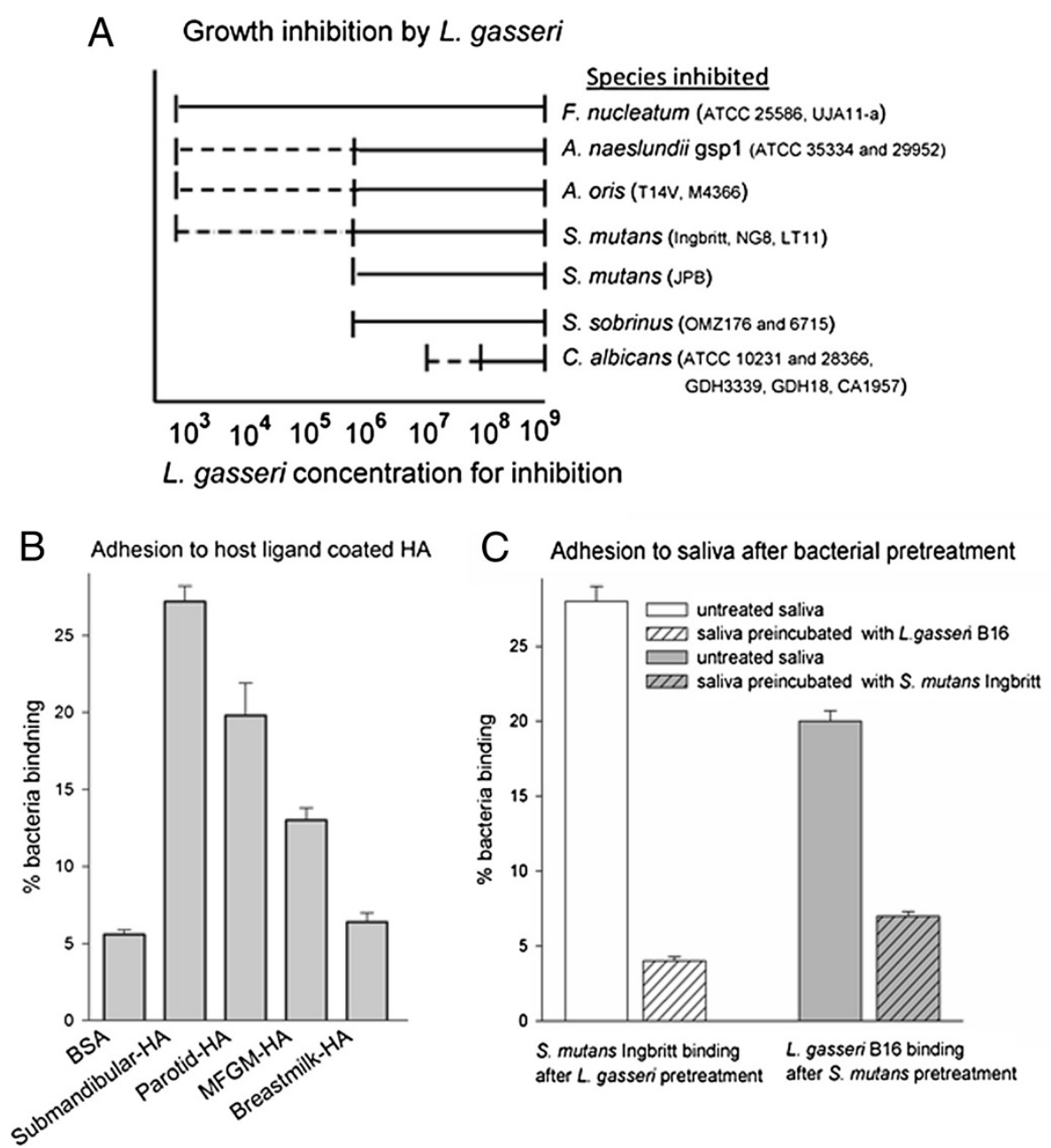

Figure 3 Probiotic traits of L. gasseri isolates. (A) Growth inhibition by L. gasseri. Growth of selected oral bacteria exposed to increasing concentrations of L. gasseri strain (B16) isolated from saliva. —_ completely inhibited growth (score 0), - - - - partially inhibited growth (score 1), and blank no effect on growth (score 2). (B) Adhesion to host ligand coated hydroxyapatite (HA). Adhesion of L. gasseri strain B16 to HA in the presence of selected host ligands. Data are presented as mean \pm SEM for percent bacteria binding of added cells. Host ligands were from one adult donor of submandibular/sublingual saliva, two adult donors of parotid saliva and breast milk and purified MFGM (1 mg/mL). Background binding to bovine serum albumin blocked beads (no saliva) was $<6 \%$. (C) Adhesion to saliva-coated hydroxyapatite after bacterial pretreatment. Adhesion of L. gasseri strain B16 or S. mutans strain Ingbritt to parotid and submandibular/sublingual saliva before and after preincubation with S. mutans strain Ingbritt or L. gasseri strain B16, respectively. Data are presented as mean \pm SEM for percent bacteria binding of added cells. Background binding to bovine serum albumin blocked beads (no saliva) was $<6 \%$.

Table 3 L. gasseri adhesion to saliva coated hydroxyapatite and aggregation in saliva

\begin{tabular}{|c|c|c|c|c|}
\hline \multirow[b]{2}{*}{ L. gasseri } & \multicolumn{2}{|c|}{ Parotid saliva } & \multicolumn{2}{|c|}{ Submandibular/sublingual saliva } \\
\hline & Adhesion $^{1}$ & Aggregation $^{2}$ & Adhesion $^{1}$ & Aggregation $^{2}$ \\
\hline Isolate B16 & ++ & ++ & +++ & +++ \\
\hline Isolate B1 & + & + & ++ & ++ \\
\hline Isolate L10 & + & ++ & ++ & +++ \\
\hline Isolate A241 & + & + & ++ & ++ \\
\hline Isolate A274 & + & ++ & ++ & +++ \\
\hline Type strain $31451^{\top}$ & ++ & ++ & +++ & +++ \\
\hline
\end{tabular}

${ }^{1} 62.5 \times 10^{6}$ bacterial cells were added into each test well. + binding of $<15 \%$ of added bacterial cells, $++\geq 15$ to $<20 \%$, and $+++\geq 20 \%$.

$2_{-}=$aggregation score 0 (no visible aggregates), + aggregation score 1 (small uniform aggregates), ++ aggregation score 2 (more aggregates of slightly larger size than 1), +++ aggregation score 3 (more and slightly larger aggregates than 2) [30]. Adhesion buffer was used a negative control (score 0 ) and S. mutans strain Ingbritt as positive control (score +++ ) [18]. 


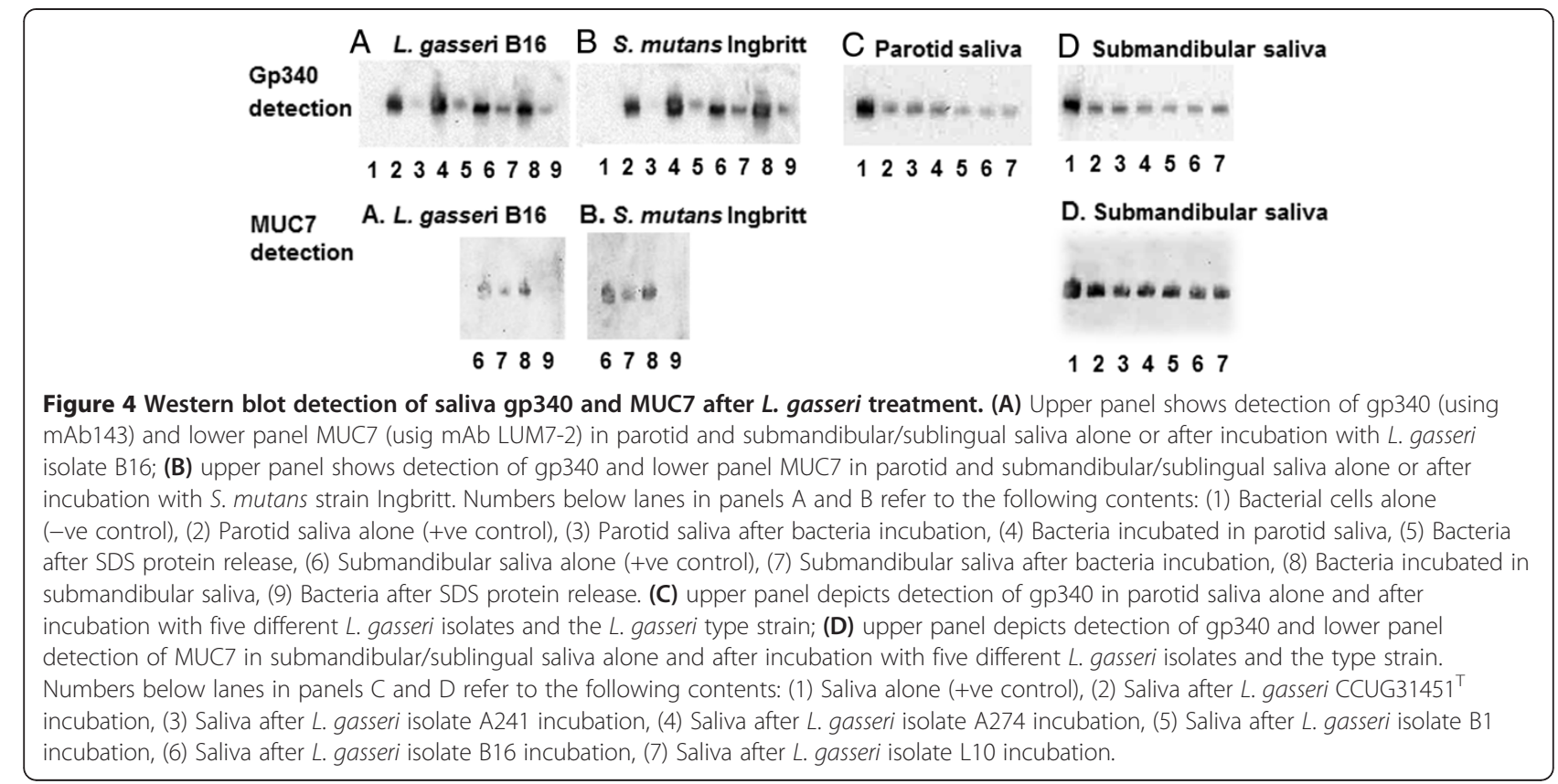

traits, including attachment to epithelial cells, growth inhibition, replacement or binding inhibition of pathogens and immunomodulation [46,47]. L. gasseri strains from feces and human milk have been observed to $(i)$ adhere to intestinal epithelial cells and intestinal mucus (mainly MUC2) [48,49], (ii) produce bacteriocins [50,51], (iii) reduce mutagenic enzymes in feces [52], (iv) stimulate macrophages and lymphocytes, $(v)$ modulate the immune systems through the toll receptors [53] and (vi) show resistance to gastric and small intestine fluids [49]. In the current report, salivary L. gasseri demonstrated several probiotic traits including: attachment to the human gingival epithelial cells HGEPp.05 and saliva, growth inhibition of several oral species and reduced attachment of the cariogenic S. mutans to saliva. Potential in vivo effects on the microbiota as well as short and long term biological

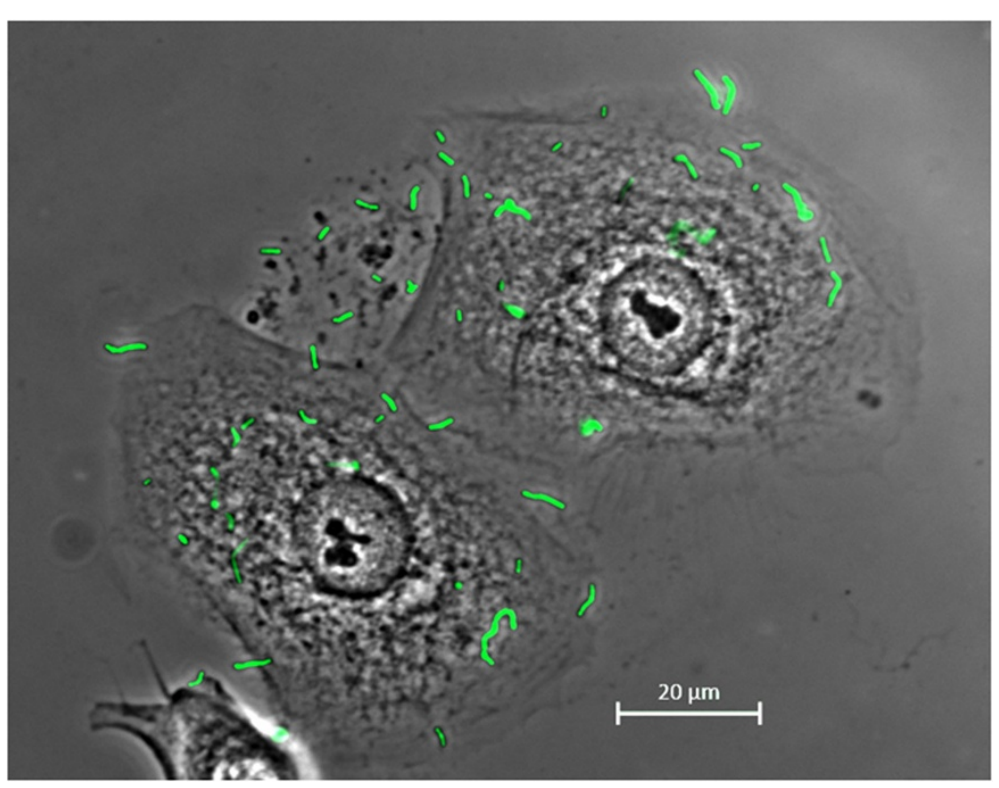

Figure 5 Adhesion of $L$. gasseri to human epithelial cells. Field of view containing differentiated human gingival epithelial cells (HGEP.05) and fluorescently stained L. gasseri A274 (in green). Bacteria were detected only in association with gingival epithelial cells. Images were captured using a Zeiss imager Z1 upright microscope. Bars in panels equal $20 \mu \mathrm{m}$. 
processes remain to be demonstrated, but in vivo effects might be anticipated as we observed growth inhibition at L. gasseri concentrations as low as $10^{3} \mathrm{CFU} / \mathrm{mL}$, which are the levels reported for human milk $[6,16]$.

Studies have reported that breast milk contains $L$. gasseri, L. salivarius and L. fermentum, of which L. gasseri was the most prevalent species $[15,16]$, but the prevalence of L. gasseri detection has not been reported. We cultured Lactobacillus species, predominantly L. gasseri, from approximately one third of breastfed infants with lower to non-detectable levels from formula-fed infants. This is consistent with our previous rapport [13]. Breast milk was not collected from the mothers, so we do not know whether detection of L. gasseri in infants reflects its presence in the mother's milk. Other possible reasons for variability of $L$. gasseri detection in infants saliva include: individuality in adhesion site blocking on L. gasseri (presumably by saliva because $L$. gasseri aggregated in saliva but not in milk), and phenotypic host receptor variation. Few studies have examined host receptors for, and adhesion properties of, L. gasseri and lactobacilli in general [54]. Binding of various lactobacilli species to saliva gp340 [33], peroxidase [33] and gastric and intestinal mucus [46,48], blood group antigens and histone H3 [55] has been reported. Most of these host receptors are heavily glycosylated and several carry blood group antigens $[55,56]$, which is consistent with the present findings of more avid binding of L. gasseri to submandibular/sublingual saliva, gp340, MUC7 and MFGM. Interestingly, it was reported recently [57] that the innate immunity peptide LL37, which has been detected in the mouth on epithelial cells and in submandibular/sublingual saliva [58], alters the surface of $L$. crispatus with a possible influence on its adhesive traits [57]. Since gp340 and MUC7 (here identified as host receptors for L. gasseri binding) exist as polymorphic variants [34,35], and phenotypic variation in gp340 relates to $S$. mutans adhesion avidity (gp340 here shown as shared host receptor for $L$. gasseri and $S$. mutans), it seems possible that phenotypic host receptor variation can influence $L$. gasseri colonization in breastfed infants. This would suggest that bacterial acquisition in infancy, and potential beneficial effects from probiotic products, may vary among individuals.

Pre-incubation of L. gasseri with saliva reduced detectable salivary gp340, and thus the observed $S$. mutans binding to gp340, suggesting that L. gasseri and S. mutans share a binding epitope in saliva. Competitive binding has previously been observed between $S$. mutans and other lactobacilli species with gp340 [33]. L. gasseri strains have also been shown to compete with, displace, and inhibit the adhesion of the enteric pathogens Cronobacter sakazakii and Clostridium difficile to intestinal mucus [48]. This suggests that L. gasseri may play a similar role in the oral cavity as has been observed in the gut. Although saliva from adults was used in the present study, gp340 has been detected in saliva in infants [19]. Saliva has been shown to have a stable pattern of salivary proteins and glycoproteins from early infancy, with the exception of albumin and the mucins, with early dominance of MUC7 later followed by MUC5B [59].

Infants fed the MFGM supplemented formula tended to have higher oral levels of total lactobacilli and $L$. gasseri than infants fed a standard formula. This could reflect that MFGM provides a wide range of potential carbohydrate binding epitopes on glycoproteins and glycolipids, and that L. gasseri bound to purified MFGM coated on hydroxyapatite (present study). An increased content of MFGM supplementation could potentially foster acquisition of L. gasseri and/or other Lactobacillus species in the gastro-intestinal tract, but this concept needs further study.

\section{Conclusions}

Our study findings lead us to conclude that the oral cavities of breastfed infants are colonized by lactobacilli more frequently than formula-fed infants and that $L$. gasseri is the dominant Lactobacillus species. L. gasseri from infants has characteristics consistent with probiotic properties, which could influence the composition of the oral microbiota in infants.

\section{Competing interests}

$\mathrm{OH}$ is member of the scientific advisory board of Semper $\mathrm{AB}$.

\section{Authors' contributions}

IJ, MD, OH, ACRT planned, designed and financed the study. NT coordinated and organized infant participation and sampling. NRV, and PLH coordinated the oral part of the study. NRV, CÖ, CK (qPCR experiments), RC

(microbiological identifications) performed laboratory experiments. NRV and IJ performed statistics and drafted the manuscript. All authors contributed to completion of the manuscript and approved it.

\section{Acknowledgements}

The present study was supported by Vinnova, Semper AB, Västerbotten County Council (TUA), The Swedish Research Council funded National School of Odontological Sciences, and by Public Health Service Grants DE-021796 and T32 DE-007327 from the National Institute of Dental and Craniofacial Research, USA.

\section{Author details}

${ }^{1}$ Department of Odontology/Cariology section, Umeå University, Umeå, Sweden. ${ }^{2}$ Department of Clinical Sciences/Pediatrics section, Umeå University, Umeå, Sweden. ${ }^{3}$ Department of Microbiology, The Forsyth Institute, Cambridge, MA 02142, USA. ${ }^{4}$ Department of Oral Medicine, Infection and Immunity, Harvard School of Dental Medicine, Harvard University, Boston, MA 02115, USA. ${ }^{5}$ Department of Odontology/ Microbiology section, Umeå University, Umeå, Sweden.

Received: 11 March 2013 Accepted: 8 August 2013 Published: 15 August 2013

\section{References}

1. Ahrne S, Nobaek S, Jeppsson B, Adlerberth I, Wold AE, Molin G: The normal Lactobacillus flora of healthy human rectal and oral mucosa. J Appl Microbiol 1998, 85:88-94. 
2. Preidis GA, Versalovic J: Targeting the human microbiome with antibiotics, probiotics, and prebiotics: gastroenterology enters the metagenomics era. Gastroenterology 2009, 136:2015-2031.

3. Tsai YT, Cheng PC, Pan TM: The immunomodulatory effects of lactic acid bacteria for improving immune functions and benefits. Appl Microbiol Biotechnol 2012, 96:853-862.

4. Food and Agriculture Organization/World health Organization (FAO/WHO): Guidelines for the evaluation of probiotics in food: report of a joint FAO/WHO working group on drafting guidelines for the evaluation of probiotics in food. Ontario, Canada; 2002.

5. Rupa $P$, Mine $Y$ : Recent advances in the role of probiotics in human inflammation and gut health. J Agric Food Chem 2012, 60:8249-8256.

6. West $C E$, Hammarström ML, Hernell $\mathrm{O}$ : Probiotics during weaning reduce the incidence of eczema. Pediatr Allergy Immunol 2009, 20:430-437.

7. Million M, Raoult D: Species and strain specificity of Lactobacillus probiotics effect on weight regulation. Microb Pathog 2013, 55:52-54.

8. Van Houte J: Bacterial specificity in the etiology of dental caries. Int Dent J 1980, 30:305

9. Aas JA, Griffen AL, Dardis SR, Lee AM, Olsen I, Dewhirst FE, Leys EJ, Paster BJ: Bacteria of dental caries in primary and permanent teeth in children and young adults. J Clin Microbiol 2008, 46:1407-1417.

10. Haukioja A: Probiotics and oral health. Eur J Dent 2010, 4:348-355.

11. Simark-Mattsson C, Emilson CG, Hakansson EG, Jacobsson C, Roos K, Holm S: Lactobacillus-mediated interference of mutans streptococci in caries-free vs. caries-active subjects. Eur J Oral Sci 2007, 115:308-314.

12. Kanasi E, Johansson I, Lu SC, Kressin NR, Nunn ME, Kent R Jr, Tanner AC: Microbial risk markers for childhood caries in pediatricians' offices. J Dent Res 2010, 89:378-383.

13. Holgerson PL, Vestman NR, Claesson R, Ohman C, Domellof M, Tanner AC, Hernell O, Johansson I: Oral microbial profile discriminates breast-fed from formula-fed infants. J Pediatr Gastroenterol Nutr 2013, 56:127-136.

14. Straetemans MM, van Loveren C, de Soet JJ, de Graaff J, ten Cate JM: Colonization with mutans streptococci and lactobacilli and the caries experience of children after the age of five. J Dent Res 1998 77:1851-1855

15. Martin $\mathrm{R}$, Langa $\mathrm{S}$, Reviriego $\mathrm{C}$, Jiminez $\mathrm{E}$, Marin $\mathrm{ML}$, Xaus J, Fernandez L, Rodriguez JM: Human milk is a source of lactic acid bacteria for the infant gut. J Pediatr 2003, 143:754-758.

16. Solis G, de Los Reyes-Gavilan CG, Fernandez N, Margolles A, Gueimonde M: Establishment and development of lactic acid bacteria and bifidobacteria microbiota in breast-milk and the infant gut. Anaerobe 2010, 16:307-310.

17. Aimutis WR: Bioactive properties of milk proteins with particular focus on anticariogenesis. J Nutr 2004, 134:989-995.

18. Danielsson Niemi L, Hernell O, Johansson I: Human milk compounds inhibiting adhesion of mutans streptococci to host ligand-coated hydroxyapatite in vitro. Caries Res 2009, 43:171-178.

19. Wernersson J, Danielsson Niemi L, Einarson S, Hernell O, Johansson I: Effects of human milk on adhesion of Streptococcus mutans to salivacoated hydroxyapatite in vitro. Caries Res 2006, 40:412-417.

20. Ballard O, Morrow AL: Human milk composition: nutrients and bioactive factors. Pediatr Clin North Am 2013, 60:49-74.

21. Liao Y, Alvarado R, Phinney B, Lonnerdal B: Proteomic characterization of human milk fat globule membrane proteins during a 12 month lactation period. J Proteome Res 2011, 10:3530-3541.

22. Cavaletto $M$, Giuffrida $M G$, Conti A: Milk fat globule membrane components-a proteomic approach. Adv Exp Med Biol 2008, 606:129-141.

23. Charlwood J, Hanrahan S, Tyldesley R, Langridge J, Dwek M, Camilleri P: Use of proteomic methodology for the characterization of human milk fat globular membrane proteins. Anal Biochem 2002, 301:314-324.

24. Lonnerdal B: Bioactive proteins in breast milk. J Paediatr Child Health 2013, 49(Suppl 1):1-7.

25. Brisson G, Payken HF, Sharpe JP, Jimenez-Flores R: Characterization of Lactobacillus reuteri interaction with milk fat globule membrane components in dairy products. J Agric Food Chem 2010, 58:5612-5619.

26. Clare DA, Zheng Z, Hassan HM, Swaisgood HE, Catignani GL: Antimicrobial properties of milkfat globule membrane fractions. J Food Prot 2008, 71:126-133.

27. Byun R, Nadkarni MA, Chhour KL, Martin FE, Jacques NA, Hunter N: Quantitative analysis of diverse Lactobacillus species present in advanced dental caries. J Clin Microbiol 2004, 42:3128-3136.
28. Truelove EL, Bixler D, Merritt AD: Simplified method for collection of pure submandibular saliva in large volumes. J Dent Res 1967, 46:1400-1403.

29. Gibbons RJ, Hay DI: Human salivary acidic proline-rich proteins and statherin promote the attachment of Actinomyces viscosus LY7 to apatitic surfaces. Infect Immun 1988, 56:439-445.

30. Hallberg K, Hammarstrom KJ, Falsen E, Dahlen G, Gibbons RJ, Hay DI, Stromberg N: Actinomyces naes/undii genospecies 1 and 2 express different binding specificities to $\mathrm{N}$-acetyl-beta-D-galactosamine, whereas Actinomyces odontolyticus expresses a different binding specificity in colonizing the human mouth. Oral Microbiol Immunol 1998, 13:327-336.

31. Lofling J, Diswall M, Eriksson S, Boren T, Breimer ME, Holgersson J: Studies of Lewis antigens and $\mathrm{H}$. pylori adhesion in $\mathrm{CHO}$ cell lines engineered to express Lewis b determinants. Glycobiology 2008, 18:494-501.

32. Boren T, Falk P, Roth KA, Larson G, Normark S: Attachment of Helicobacter pylori to human gastric epithelium mediated by blood group antigens. Science 1993, 262:1892-1895.

33. Haukioja A, Loimaranta $V$, Tenovuo J: Probiotic bacteria affect the composition of salivary pellicle and streptococcal adhesion in vitro. Oral Microbiol Immunol 2008, 23:336-343.

34. Eriksson C, Frangsmyr L, Danielsson Niemi L, Loimaranta V, Holmskov U, Bergman T, Leffler H, Jenkinson HF, Stromberg N: Variant size- and glycoforms of the scavenger receptor cysteine-rich protein gp-340 with differential bacterial aggregation. Glycoconj J 2007, 24:131-142.

35. Wickström C, Christersson C, Davies J, Carlstedt I: Macromolecular organization of saliva: identification of 'insoluble' MUC5B assemblies and non-mucin proteins in the gel phase. Biochem J 2000, 351:421.

36. Ellis KJ, Yao M, Shypailo RJ, Urlando A, Wong WW, Heird WC: Body-composition assessment in infancy: air-displacement plethysmography compared with a reference 4-compartment model. Am J Clin Nutr 2007, 85:90-95.

37. Knol J, Scholtens P, Kafka C, Steenbakkers J, Gro S, Helm K, Klarczyk M, Schopfer H, Bockler HM, Wells J: Colon microflora in infants fed formula with galacto- and fructo-oligosaccharides: more like breast-fed infants. J Pediatr Gastroenterol Nutr 2005, 40:36-42.

38. Bylesjö M, Rantalainen M, Cloarec O, Nicholson JK, Holmes E, Trygg J: OPLS discriminant analysis: combining the strengths of PLS-DA and SIMCA classification. Journal of Chemometrics 2006, 20:341-351.

39. Sjöström M, Wold S, Söderström B: PLS discriminant plots. Amsterdam: Elsevier; 1986

40. Holmes E, Kinross J, Gibson GR, Burcelin R, Jia W, Pettersson S, Nicholson JK: Therapeutic modulation of microbiota-host metabolic interactions. Sci Trans Med 2012, 4:137rv6.

41. Holscher HD, Faust KL, Czerkies LA, Litov R, Ziegler EE, Lessin H, Hatch T, Sun S, Tappenden KA: Effects of prebiotic-containing infant formula on gastrointestinal tolerance and fecal microbiota in a randomized controlled trial. JPEN J Parenter Enteral Nutr 2012, 36(Suppl 1):95S-105S.

42. Lif Holgerson P, Harnevik L, Hernell O, Tanner AC, Johansson I: Mode of birth delivery affects oral microbiota in infants. J Dent Res 2011, 90:1183-1188.

43. Ahrne S, Lonnermark E, Wold AE, Aberg N, Hesselmar B, Saalman R, Strannegard IL, Molin G, Adlerberth I: Lactobacilli in the intestinal microbiota of Swedish infants. Microbes and infection / Institut Pasteur 2005, 7:1256-1262.

44. Kirtzalidou E, Pramateftaki P, Kotsou M, Kyriacou A: Screening for lactobacilli with probiotic properties in the infant gut microbiota. Anaerobe 2011, 17:440-443

45. Kullen MJ, Sanozky-Dawes RB, Crowell DC, Klaenhammer TR: Use of the DNA sequence of variable regions of the 16S rRNA gene for rapid and accurate identification of bacteria in the Lactobacillus acidophilus complex. J Appl Microbiol 2000, 89:511-516.

46. Chauviere G, Coconnier MH, Kerneis S, Fourniat J, Servin AL: Adhesion of human Lactobacillus acidophilus strain LB to human enterocyte-like Caco-2 cells. J Gen Microbiol 1992, 138:1689-1696.

47. Kotzamanidis C, Kourelis A, Litopoulou-Tzanetaki E, Tzanetakis N, Yiangou M: Evaluation of adhesion capacity, cell surface traits and immunomodulatory activity of presumptive probiotic Lactobacillus strains. Int J Food Microbiol 2010, 140:154-163.

48. Ferreira CL, Grzeskowiak L, Collado MC, Salminen S: In vitro evaluation of Lactobacillus gasseri strains of infant origin on adhesion and aggregation of specific pathogens. J Food Prot 2011, 74:1482-1487.

49. Rodrigues Da Cunha L, Fortes Ferreira CL, Durmaz E, Goh YJ, Sanozky-Dawes $\mathrm{R}$, Klaenhammer T: Characterization of Lactobacillus gasseri isolates from a breast-fed infant. Gut microbes 2012, 3:15-24. 
50. Arakawa K, Kawai Y, lioka H, Tanioka M, Nishimura J, Kitazawa H, Tsurumi K, Saito T: Effects of gassericins $A$ and $T$, bacteriocins produced by Lactobacillus gasseri, with glycine on custard cream preservation. J Dairy Sci 2009, 92:2365-2372.

51. Kawai Y, Saito T, Toba T, Samant SK, Itoh T: Isolation and characterization of a highly hydrophobic new bacteriocin (gassericin A) from Lactobacillus gasseri LA39. Biosci Biotechnol Biochem 1994, 58:1218-1221.

52. Pedrosa MC, Golner BB, Goldin BR, Barakat S, Dallal GE, Russell RM: Survival of yogurt-containing organisms and Lactobacillus gasseri (ADH) and their effect on bacterial enzyme activity in the gastrointestinal tract of healthy and hypochlorhydric elderly subjects. Am J Clin Nutr 1995, 61:353-359.

53. Gomez-Llorente C, Munoz S, Gil A: Role of Toll-like receptors in the development of immunotolerance mediated by probiotics. Proc Nutr Soc 2010, 69:381-389.

54. Edelman SM, Lehti TA, Kainulainen V, Antikainen J, Kylvaja R, Baumann M, Westerlund-Wikstrom B, Korhonen TK: Identification of a high-molecular-mass Lactobacillus epithelium adhesin (LEA) of Lactobacillus crispatus ST1 that binds to stratified squamous epithelium. Microbiology 2012, 158:1713-1722.

55. Watanabe M, Kinoshita H, Huang IN, Eguchi K, Tsurumi T, Kawai Y, Kitazawa H, Kimura K, Taketomo N, Kikuchi D, et al: An Adhesin-Like Protein, Lam29, from Lactobacillus mucosae ME-340 Binds to Histone $\mathrm{H} 3$ and Blood Group Antigens in Human Colonic Mucus. Biosci Biotechnol Biochem 2012, 76:1655-1660.

56. Van Tassell ML, Miller MJ: Lactobacillus adhesion to mucus. Nutrients 2011, 3:613-636.

57. Kainulainen V, Loimaranta V, Pekkala A, Edelman S, Antikainen J, Kylvaja R, Laaksonen M, Laakkonen L, Finne J, Korhonen TK: Glutamine synthetase and glucose-6-phosphate isomerase are adhesive moonlighting proteins of Lactobacillus crispatus released by epithelial cathelicidin LL-37. J Bacteriol 2012, 194:2509-2519.

58. Murakami M, Ohtake T, Dorschner RA, Gallo RL: Cathelicidin antimicrobial peptides are expressed in salivary glands and saliva. J Dent Res 2002, 81:845-850.

59. Ruhl S, Rayment SA, Schmalz G, Hiller KA, Troxler RF: Proteins in whole saliva during the first year of infancy. J Dent Res 2005, 84:29-34.

doi:10.1186/1471-2180-13-193

Cite this article as: Romani Vestman et al:: Characterization and in vitro properties of oral lactobacilli in breastfed infants. BMC Microbiology 2013 13:193.

\section{Submit your next manuscript to BioMed Central and take full advantage of:}

- Convenient online submission

- Thorough peer review

- No space constraints or color figure charges

- Immediate publication on acceptance

- Inclusion in PubMed, CAS, Scopus and Google Scholar

- Research which is freely available for redistribution 